\section{OPTIMIZATION OF BELLOWS} \section{AND TUBES CUTTING BY DISC KNIFE TO ACHIEVE THE MINIMUM BURR SIZE}

RADEK CADA, PAVEL LOSAK

Department of Mechanical Technology, Faculty of Mechanical Engineering, VSB - Technical University of Ostrava,

Ostrava, Czech Republic

DOI: 10.17973/MMSJ.2021_12_2021104

radek.cada@vsb.cz

The paper solves the determination of the optimal size of the shear gap when dividing components with a circular cross section (hydroformed metal bellows and tubes) with a disc knife to achieve the smallest burr size on the divided surfaces. The analyzes were performed on bellows with an outer diameter of $15 \mathrm{~mm}$ and a wall thickness of $0.4 \mathrm{~mm}$. During the experiments, the size of the shear gap between the inner disc knife and the outer knife was changed, and the pressing force of the inner disc knife was changed. The experiments were carried out using a cutting tool after 20,000 cuts and after 120,000 cuts. The optimal size of the cutting gap was determined, allowing the minimum size of the burr to be achieved, thus reducing the time to remove it by brushing or tumbling in the subsequent operation. The mentioned procedure can be applied to analogous cases of division.

KEYWORDS

Shear gap, cutting tool, disc knife, burr, bellow, tube, optimization.

\section{INTRODUCTION}

In aircrafts, passenger cars, buildings, air conditioning, etc., there are systems of ducts consisting of bellows and tubes. Bellows tubes and hoses are used to transport liquids, gases, or other media. Depending on the operating conditions, there are usually requirements for resistance to corrosion and ageing and resistance to high temperatures or pressures. Some bellows are fitted with an outer metal braid. The starting material for tube production is strip steel, usually produced by continuous casting [Velicka 2013, Pyszko 2018], rolled cold in the form of coils. An option to produce corrosion-resistant components is the use of hot dip galvanized blanks [Vontorova 2018]. They are mainly used in the automotive industry. When it forms, its tribological properties must also be taken into account [Evin 2011]. The mechanical properties of sheet metal can be increased in some applications, for example, by the unconventional forming method DRECE (Dual Rolls Equal Channel Extrusion) [Hilser 2014, Rusz 2019, Rusz 2020]. Strip steel for the production of bellows and tubes is progressively curved in the line. For forming, the material must have sufficient formability [Cada 1997, Evin 2012, Novak 2019]. The method of deformation networks can be used to analyze deformation during forming [Cada 2003]. Curved strip steel is subsequently welded. After welding, the mechanical properties of the material are important, especially in the heat-affected zone [Sternadelova 2019]. Weld technology affects the deformation properties of steels [Evin 2016], as well as the resistance to corrosion. The subsequent calibration of the tube or wave that forms on the bellows is followed by cutting [Losak 2021] and eventually bending to the desired shape. To ensure the stability of the production process, machine maintenance must be managed, preferably using so-called totally productive maintenance [Necas 2019]. Achieving maximum production productivity while eliminating waste can be achieved, for example, by using the value stream mapping method [Sajdlerova 2015].

\subsection{Description of the Bellows}

A bellow (see Fig. 1) is a tube that is corrugated around its circumference by mechanical or liquid forming (hydroforming) [Rihacek 2019], with waves that are rotationally symmetrical and parallel to each other. This gives the necessary properties of the machine component, such as elasticity. The bellows are divided into many types according to their purpose and construction.

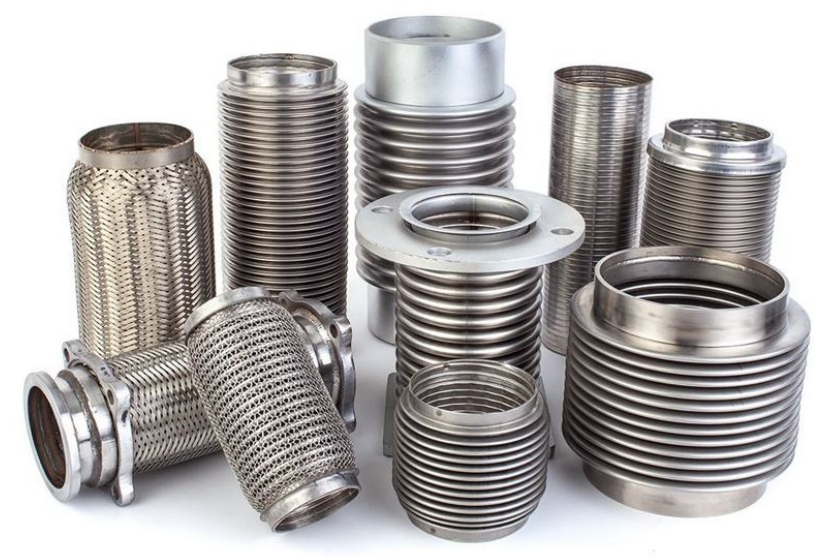

Figure 1. Bellows - tubes corrugated around their circumference

The main types of bellows include:

a) bellows tubes and hoses (Bellows tubes are used to form non-moving parts of ducts, i.e., they are bent during manufacture or installation but not in service. In contrast, bellows hoses are designed for repeated bending.),

b) compensators (These are flexible components used to compensate for displacements that occur in the distribution system due to external forces, temperature differences, or vibrations.),

c) metal bellows used to seal valves and spindles (They are used, for example, as flexible sealing elements for stem sealing in vacuum valves.),

d) bellows for motor vehicles (These are used, for example, to return exhaust gases between the radiator and the check valve in the engine area, thereby significantly reducing pollutant emissions and increasing the efficiency of the equipment. The bellows are also used to remove high-frequency vibrations caused by the turbocharger, which reduces noise levels. These bellows exhibit high resistance to corrosion, operating temperatures, and high operating pressures.).

\subsection{Cutting of Bellows and Tubes, Formation of Burrs}

The following technologies can be used for cutting of bellows and tubes:

a) cutting with an internal disc knife and an external knife (This is cutting with a single-purpose machine. The inner disc knife is held in a spindle with a defined speed, rotates around its axis, and continuously increases the radius 
described. The advantage of the method is minimal waste and high productivity.),

b) a cutting (using a circular knife and an internal mandrel on the lathe),

c) grooving on the lathe (high cutting accuracy is an advantage),

d) band sawing (the cutting gap is usually one to two thirds smaller than with circular or frame saws, and the cutting surface has a high surface quality).

The burrs resulting from the cutting of bellows and tubes can be divided into the following:

a) burrs produced on the outer edge of the bellow or tube by the action of the tool from the centre of the tube axis towards the outer surface of the bellow or tube (cutting with the inner disc knife and the outer knife),

b) burrs on the inner edge of the bellow or tube, caused by the action of the tool from the outer surface of the bellow or tube towards the axis of the bellow or tube (cutting or grooving on the lathe),

c) burrs on the inner and outer edges of the bellow or tube caused by band sawing.

\section{ANALYSIS OF THE TECHNOLOGY OF CUTTING BELLOWS WITH A CIRCULAR KNIFE}

\subsection{Properties of the Bellows Used for the Analysis}

A bellow with an outer diameter of $15 \mathrm{~mm}$, with a wall thickness of $0.4 \mathrm{~mm}$, of stainless steel 1.4541, was selected for cutting analysis with a circular knife. Tab. 1 shows the mechanical properties of the material and Tab. 2 shows the chemical composition of the material.

\begin{tabular}{c|c|c|c|}
$\begin{array}{c}\text { Yield } \\
\text { Strength } \\
\boldsymbol{R}_{\mathrm{p} 02} \\
(\mathrm{MPa})\end{array}$ & $\begin{array}{c}\text { Modulus } \\
\text { of Elasticity } \\
\text { at } 20^{\circ} \mathrm{C} E(\mathrm{GPa})\end{array}$ & $\begin{array}{c}\text { Tensile } \\
\text { Strength } \\
\boldsymbol{R}_{\mathrm{m}}(\mathrm{MPa})\end{array}$ & $\begin{array}{c}\text { Ductility } \\
\text { (transverse) } \\
\boldsymbol{A}(\%)\end{array}$ \\
\hline 200 & 200 & $500-700$ & min. 40 \\
\hline
\end{tabular}

Table 1. Mechanical properties of material 1.4541/X6CrNiTiB18-10 at room temperature in annealed condition [23]

\begin{tabular}{|c|c|c|c|c|}
\hline Element & $\mathbf{C}$ & $\mathrm{Si}$ & $\mathrm{Mn}$ & $\mathrm{Cr}$ \\
\hline Min. & - & - & - & 17.00 \\
\hline Max. & 0.08 & 1.00 & 2.00 & 19.00 \\
\hline Element & $\mathbf{N i}$ & $\mathrm{Ti}$ & $\mathbf{P}$ & $\mathbf{S}$ \\
\hline Min. & 9.00 & $5 \times \mathrm{C}$ & - & - \\
\hline Max. & 12.00 & 0.70 & 0.045 & 0.015 \\
\hline
\end{tabular}

Table 2. Chemical composition of material $1.4541 /$ X6CrNiTiB18-10 (wt \%) [23]

\subsection{Machine Used to Cut Bellows}

Analysis of the burr size after cutting with a disc knife was performed on a special machine for cutting bellows and tubes made to order by AuTech GmbH (Germany). The photo of this machine was not allowed to be published by the company producing the bellows. The machine works with two spindles in which the inner disc knives are clamped. Cutting is performed using internal knives that rotate around their axis with an ascending radial spiral feed. During the working movement, the inner tool rotates at a defined speed of $40 \mathrm{~s}^{-1}$. The cutting process begins with the position of the tool on the axis of the bellows and gradually increases the distance from the axis, and there is a gradual cutting of the wall of the bellows. During the final penetration of the disc knife blade by the bellows, the remaining material is cut against the outer knife. It is therefore a combined division, in which cutting and shearing take place.

For the correct operation of the machine and to achieve the minimum size of burrs at the edge of the cutting surface, it is necessary to precisely adjust the tools, i.e. the inner and outer knives, to the optimal cutting gap before starting the cutting. Since this adjustment has been performed intuitively in the production plant, an experimental determination of the optimal size of the shear gap and the size of the pressing force was performed.

\subsection{Objectives of Burr Size Analysis}

The analysis aimed to determine the dependence between the burr size on the edge of the cutting surface of products with a circular cross section (bellows and tubes) and the cutting gap between the inner disc knife and the outer split knife, as well as to determine the appropriate pressure of the inner disc knife.

Another objective was to determine the maximum values of the burr size. The manufacturer requires that the maximum burr size of $0.17 \mathrm{~mm}$ is not exceeded at any point on the cutting surface, due to the subsequent technology of deburring by tumbling.

\section{EXPERIMENTAL PROCEDURE}

\subsection{Parameters when cutting bellows with a circular knife}

In the experiments, the inner disc knife pressure was used at two values $-0.20 \mathrm{MPa}$ and the size $0.25 \mathrm{MPa}$, and the size of the shear gap was varied in the 0.04 to $0.10 \mathrm{~mm}$ interval in ascending increments of $0.01 \mathrm{~mm}$. In total, there were 14 settings for the cutting tool. At each cutting tool setting, five bellows were cut at each end of the bellows to provide ten shear areas for the evaluation of the burr size.

The pressure value of the inner disc knife is set in the programming environment of the machine control software (see 2.2). When cutting the bellows, the inner disc knife is gradually moved in a radial direction in a spiral against the surface of the bellows wall.

To evaluate the optimal size of the shear gap over the lifetime of the shearing tool, experiments were conducted using two sets of tools (inner disc knife and outer split knife), where the former had wear after 120,000 working cycles and the latter had wear after 20,000 working cycles.

The total number of shear surfaces evaluated on the bellows was therefore 280 (140 for each set of tools).

\subsection{Measurement of Burrs on Split Surfaces of Bellows}

Measurement of the size of the burrs at the edges of the shear surfaces of the bellows was performed using a Keyence IM6225 digital profile projector (see Figure 2). It is a visual inspection system that performs measurements in place of optical comparators, measuring microscopes, and optical CMMs. The use of Keyence IM-6225 reduced the inspection time and removed all subjectivity from the operator. Using this instrument, it was possible to measure the burrs at the edges of the shear surfaces of the bellows very quickly with an accuracy of $\pm 2 \mu \mathrm{m}$. 
Measurement of the size of the burrs at the edges of the faces of the bellows was carried out by two procedures, which differed depending on which set of tools they were made with.

For the first half of the bellows produced by the toolset with wear after 120,000 cycles, i.e. with a higher wear rate, the burr sizes were measured on the edges of both faces of the bellows. At each end of the bellow, burrs were measured (see Fig. 3) at four locations with an angular difference of $90^{\circ}$ from the bellows axis. Due to the high and comparable burr sizes along the circumference of the bellows face, the initial measurement point was not focused, it was chosen randomly. From the 10 measured values for each shearing tool setting, a sample mean was calculated according to equation (1) (see 3.3). This gives the mean value of the amount of burr measured at the edge of the shearing surface of the bellow.
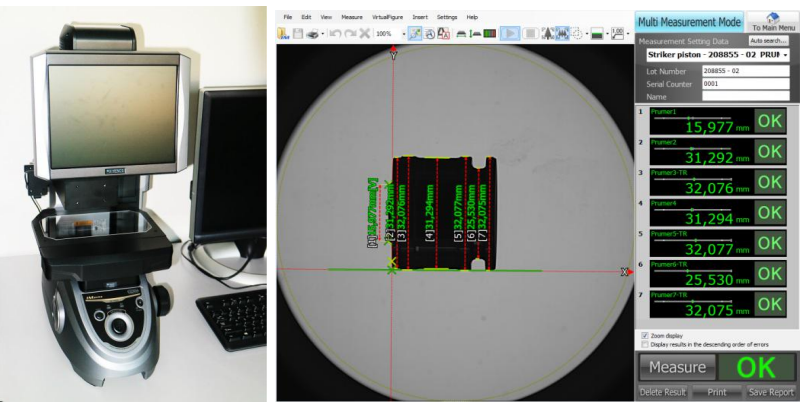

Figure 2. The principle of measurement on a digital profile projector Keyence IM-6225

The other half of the bellows, which were cut using a set of tools with less wear (a set of tools with wear after 20,000 working cycles), had a different method of measuring the amount of burr. The amount of burr at the edges of the cutting edges in the area of contact between the top and bottom of the outer blade (locations $\beta^{\prime}$ and $\beta^{\prime \prime}$ in Fig. 4) relative to the values of the amount of burr at the edges of the cutting edges measured in the areas of the center of the semicircle of cutting edges (locations $\alpha^{\prime}$ and $\alpha^{\prime \prime}$ in Fig. 4) was several times greater, and this greater burr occurred only over a circumferential length of approximately $0.3 \mathrm{~mm}$. Due to the very different magnitudes of the measured burr along the circumference of the bellows, it was necessary to precisely locate the individual locations on the circumference of the bellow.

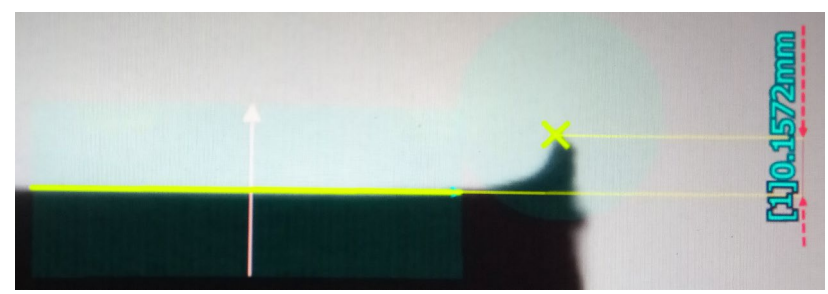

Figure 3. Measurement of the burr size at the cutting edge of a bellow on a digital profile projector Keyence IM-6225

First, the point with the highest point was precisely located, which corresponds to the point of contact between the upper and lower parts of the outer blade at the position $\beta^{\prime}$ in Fig. 4 . After measuring the largest value of the burr, the bellow was rotated $180^{\circ}$ about its axis and the measurement of the magnitude of the burr was made on the opposite side at the $\beta^{\prime \prime}$ according to Fig. 4 , which shows the same position but on the opposite side of the circular end of the bellow. Next, the burr measurement in the $\alpha^{\prime}$ region was focused by rotating the bellow so that the line passing through the points $\beta^{\prime}$ and $\beta^{\prime \prime}$ is vertical. After measuring the amount of burr at $\alpha^{\prime}$, the bellow was rotated $180^{\circ}$ and the amount of burr at $\alpha^{\prime \prime}$ was measured on the other side of the shear surface.

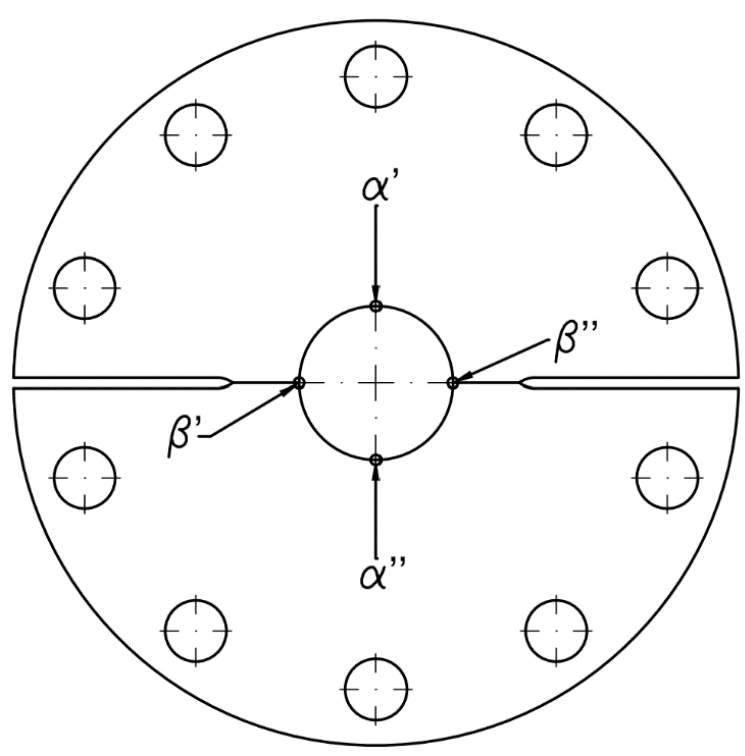

Figure 4. Locations of the measurement of the size of the burr in the split bellow concerning the shearing edges of the two parts of the outer blade $\left(\alpha^{\prime}, \alpha^{\prime \prime}\right.$ - locations at the center of the shearing edge, $\beta^{\prime}, \beta^{\prime \prime}-$ locations at the edges of the shearing edges in the area where the upper and lower parts of the outer blade meet)

\subsection{Calculation of the Random Error of the Measurement Results}

Random errors were evaluated for the burr sizes measured at the cutting edge of the bellows (see Section 2.1). As these were so-called direct measurements, they were calculated according to equations (1) to (4).

Mean value of the measured variable (sample mean):

$\bar{x}=\frac{1}{n} \sum_{i=1}^{n} \boldsymbol{X}_{i}$

where $\bar{x}$ is the sample mean (-), $n$ is the number of measured values $(-), x_{i}$ is the measured value (-) [Petrkovska 2012].

Sampling standard deviation, which is the most common characteristic of the variance of measured values:

$$
s(x)=\sqrt{\frac{\sum_{i=1}^{n}\left(x_{\mathrm{i}}-\bar{X}\right)^{2}}{n-1}}
$$

where $s(x)$ is the sampling standard deviation $(-), n$ is the number of measured values $(-), x_{i}$ is the measured value $(-), \bar{x}$ is the sample average (-). [Petrkovska 2012]

The standard deviation of the variance of the partial arithmetic means:

$s(\bar{x})=\frac{s(x)}{\sqrt{n}}$

The random error is determined based on the chosen probability and the number of measurements taken. In mechanical engineering, the most commonly chosen probability is $95 \%$ [Petrkovska 2012].

The random error (expanded uncertainty) can be calculated by multiplying the standard deviation of the variance of the partial arithmetic means by the coefficient $k$ according to the equation: 


$$
U=k \cdot s(\bar{x})
$$

where $U$ is the random error $(-), k$ is the coefficient that for the $95 \%$ probability and for 10 measurements has the value 2,262 (-) [Petrkovska 2012].

\begin{tabular}{|c|c|c|c|c|c|}
\hline \multicolumn{2}{|c|}{ Setting the Tool } & \multicolumn{4}{|c|}{ Statistical Analysis } \\
\hline $\begin{array}{c}\text { Knife } \\
\text { Pressure } \\
\text { (MPa) }\end{array}$ & $\begin{array}{l}\text { Shear } \\
\text { Gap } \\
\text { (mm) }\end{array}$ & $\begin{array}{c}\bar{x} \\
(\mathrm{~mm})\end{array}$ & $\begin{array}{c}s(x) \\
(\mathrm{mm})\end{array}$ & $\begin{array}{l}s(\bar{x}) \\
(\mathrm{mm})\end{array}$ & $\underset{(\mathrm{mm})}{U}$ \\
\hline \multirow{7}{*}{0.20} & 0.04 & 0.100 & 0.014 & 0.004 & 0.010 \\
\hline & 0.05 & 0.098 & 0.011 & 0.003 & 0.008 \\
\hline & 0.06 & 0.108 & 0.015 & 0.005 & 0.010 \\
\hline & 0.07 & 0.106 & 0.014 & 0.005 & 0.010 \\
\hline & 0.08 & 0.101 & 0.014 & 0.004 & 0.010 \\
\hline & 0.09 & 0.101 & 0.010 & 0.003 & 0.007 \\
\hline & 0.10 & 0.111 & 0.015 & 0.005 & 0.011 \\
\hline \multirow{7}{*}{0.25} & 0.04 & 0.096 & 0.012 & 0.004 & 0.009 \\
\hline & 0.05 & 0.099 & 0.013 & 0.004 & 0.009 \\
\hline & 0.06 & 0.108 & 0.012 & 0.004 & 0.008 \\
\hline & 0.07 & 0.101 & 0.011 & 0.003 & 0.008 \\
\hline & 0.08 & 0.107 & 0.012 & 0.004 & 0.009 \\
\hline & 0.09 & 0.107 & 0.011 & 0.004 & 0.008 \\
\hline & 0.10 & 0.113 & 0.018 & 0.006 & 0.013 \\
\hline
\end{tabular}

Table 3. Results of burr measurement at the cutting edge of a bellow cut by the tool set with wear after 120,000 working cycles

\begin{tabular}{|c|c|c|c|c|c|}
\hline \multicolumn{2}{|c|}{ Setting the Tool } & \multicolumn{4}{|c|}{ Statistical Analysis } \\
\hline $\begin{array}{c}\text { Knife } \\
\text { Pressure } \\
\text { (MPa) }\end{array}$ & $\begin{array}{l}\text { Shear } \\
\text { Gap } \\
(\mathrm{mm})\end{array}$ & $\begin{array}{c}\bar{x} \\
(\mathrm{~mm})\end{array}$ & $\begin{array}{c}s(x) \\
(\mathrm{mm})\end{array}$ & $\begin{array}{l}s(\bar{x}) \\
(\mathrm{mm})\end{array}$ & $\underset{(\mathrm{mm})}{U}$ \\
\hline \multirow{7}{*}{0.20} & 0.04 & 0.024 & 0.006 & 0.002 & 0.004 \\
\hline & 0.05 & 0.025 & 0.009 & 0.003 & 0.007 \\
\hline & 0.06 & 0.027 & 0.009 & 0.003 & 0.007 \\
\hline & 0.07 & 0.034 & 0.014 & 0.005 & 0.010 \\
\hline & 0.08 & 0.038 & 0.015 & 0.005 & 0.011 \\
\hline & 0.09 & 0.032 & 0.009 & 0.003 & 0.007 \\
\hline & 0.10 & 0.044 & 0.018 & 0.006 & 0.013 \\
\hline \multirow{7}{*}{0.25} & 0.04 & 0.026 & 0.005 & 0.002 & 0.004 \\
\hline & 0.05 & 0.025 & 0.006 & 0.002 & 0.004 \\
\hline & 0.06 & 0.034 & 0.010 & 0.003 & 0.007 \\
\hline & 0.07 & 0.032 & 0.012 & 0.004 & 0.008 \\
\hline & 0.08 & 0.040 & 0.022 & 0.007 & 0.016 \\
\hline & 0.09 & 0.040 & 0.014 & 0.004 & 0.010 \\
\hline & 0.10 & 0.040 & 0.023 & 0.007 & 0.016 \\
\hline
\end{tabular}

Table 4. Results of burr measurement at the cutting edge of a bellow cut by the tool set with wear after 20,000 working cycles at the points on the vertical axis of the upper and lower part of the outer blade (locations $\alpha^{\prime}$ and $\alpha^{\prime \prime}$ in Fig. 4)

\section{RESULTS}

The results of the burr measurement at the cutting edge of a bellow cut with a tool set with wear after 120,000 cycles (mean value of the burr size, sampling standard deviation, standard deviation of the variance of the partial arithmetic averages, and random error) are given in the Tab. 3.

\begin{tabular}{|c|c|c|c|c|c|}
\hline \multicolumn{2}{|c|}{ Setting the Tool } & \multicolumn{4}{|c|}{ Statistical Analysis } \\
\hline $\begin{array}{c}\text { Knife } \\
\text { Pressure } \\
\text { (MPa) }\end{array}$ & $\begin{array}{l}\text { Shear } \\
\text { Gap } \\
(\mathrm{mm})\end{array}$ & $\begin{array}{c}\bar{x} \\
(\mathrm{~mm})\end{array}$ & $\begin{array}{c}s(x) \\
(\mathrm{mm})\end{array}$ & $\begin{array}{l}s(\bar{x}) \\
(\mathrm{mm})\end{array}$ & $\underset{(\mathrm{mm})}{U}$ \\
\hline \multirow{7}{*}{0.20} & 0.04 & 0.141 & 0.020 & 0.006 & 0.014 \\
\hline & 0.05 & 0.136 & 0.020 & 0.006 & 0.014 \\
\hline & 0.06 & 0.141 & 0.016 & 0.005 & 0.011 \\
\hline & 0.07 & 0.146 & 0.022 & 0.007 & 0.016 \\
\hline & 0.08 & 0.140 & 0.008 & 0.003 & 0.006 \\
\hline & 0.09 & 0.135 & 0.020 & 0.006 & 0.014 \\
\hline & 0.10 & 0.126 & 0.016 & 0.005 & 0.012 \\
\hline \multirow{7}{*}{0.25} & 0.04 & 0.139 & 0.022 & 0.007 & 0.016 \\
\hline & 0.05 & 0.149 & 0.023 & 0.007 & 0.017 \\
\hline & 0.06 & 0.146 & 0.023 & 0.007 & 0.016 \\
\hline & 0.07 & 0.132 & 0.014 & 0.004 & 0.010 \\
\hline & 0.08 & 0.134 & 0.017 & 0.005 & 0.012 \\
\hline & 0.09 & 0.141 & 0.016 & 0.005 & 0.012 \\
\hline & 0.10 & 0.129 & 0.012 & 0.004 & 0.009 \\
\hline
\end{tabular}

Table 5. Results of burr measurement at the cutting edge of a bellow cut by the tool set with wear after 20,000 working cycles at the edges of the upper and lower part of the outer blade (locations $\beta^{\prime}$ and $\beta^{\prime \prime}$ in Fig. 4)

\begin{tabular}{|c|c|c|c|c|c|}
\hline \multicolumn{2}{|c|}{ Setting the Tool } & \multicolumn{4}{|c|}{ Statistical Analysis } \\
\hline $\begin{array}{c}\text { Knife } \\
\text { Pressure } \\
\text { (MPa) }\end{array}$ & $\begin{array}{l}\text { Shear } \\
\text { Gap } \\
(\mathrm{mm})\end{array}$ & $\begin{array}{c}\bar{x} \\
(\mathrm{~mm})\end{array}$ & $\begin{array}{c}s(x) \\
(\mathrm{mm})\end{array}$ & $\begin{array}{l}s(\bar{x}) \\
(\mathrm{mm})\end{array}$ & $\underset{(\mathrm{mm})}{U}$ \\
\hline \multirow{7}{*}{0.20} & 0.04 & 0.082 & 0.010 & 0.003 & 0.007 \\
\hline & 0.05 & 0.080 & 0.010 & 0.003 & 0.007 \\
\hline & 0.06 & 0.084 & 0.008 & 0.002 & 0.005 \\
\hline & 0.07 & 0.090 & 0.013 & 0.004 & 0.010 \\
\hline & 0.08 & 0.089 & 0.008 & 0.003 & 0.006 \\
\hline & 0.09 & 0.084 & 0.012 & 0.004 & 0.009 \\
\hline & 0.10 & 0.085 & 0.012 & 0.004 & 0.009 \\
\hline \multirow{7}{*}{0.25} & 0.04 & 0.082 & 0.011 & 0.003 & 0.008 \\
\hline & 0.05 & 0.087 & 0.010 & 0.003 & 0.007 \\
\hline & 0.06 & 0.090 & 0.013 & 0.004 & 0.009 \\
\hline & 0.07 & 0.090 & 0.010 & 0.003 & 0.007 \\
\hline & 0.08 & 0.087 & 0.015 & 0.005 & 0.011 \\
\hline & 0.09 & 0.090 & 0.007 & 0.002 & 0.005 \\
\hline & 0.10 & 0.087 & 0.014 & 0.004 & 0.010 \\
\hline
\end{tabular}

Table 6. Results of burr measurement at the cutting edge of a bellow cut by the tool set with wear after 20,000 working cycles - mean values from 4 measured points on the circumference (locations $\alpha^{\prime}, \alpha^{\prime \prime}, \beta^{\prime}$ and $\beta^{\prime \prime}$ in Fig. 4) 
The results of the burr measurement on the cutting edge of a bellow cut with a set of tools with wear after 20,000 cycles on the vertical axis of the upper and lower part of the outer blade (locations $\alpha^{\prime}$ and $\alpha^{\prime \prime}$ in Fig. 4) are given in the Tab. 4, the locations of the edges of the upper and lower parts of the outer knife (locations $\beta^{\prime}$ and $\beta^{\prime \prime}$ in Fig. 4) are given in the Tab. 5, the mean values of the four measured locations (locations $\alpha^{\prime}, \alpha^{\prime \prime}, \beta^{\prime}$ and $\beta^{\prime \prime}$ in Fig. 4) are given in the Tab. 6.

Each mean value of the burr size at the cutting edge of the bellows was calculated as a sample mean according to equation (1) (see Section 3.3). A value was calculated from the measured values at locations $\alpha^{\prime}$ and $\alpha^{\prime \prime}$ (the centre of the cutting edge of the top and bottom of the outer blade), the second from the measured values at locations $\beta^{\prime}$ and $\beta^{\prime \prime}$ (the edge of the top and bottom of the outer blade), and the third from the measured values at locations $\alpha^{\prime}, \alpha^{\prime \prime}, \beta^{\prime}$ and $\beta^{\prime \prime}$.

The mean burr sizes (with random error) at the edge of the cutting surface of the bellow cut by the toolset after 120,000 working cycles are given in the Tab. 7 . The mean burr sizes (with random error) at individual locations on the cutting surface of the bellow cut by the toolset after 20,000 working cycles are given in the Tab. 8 .

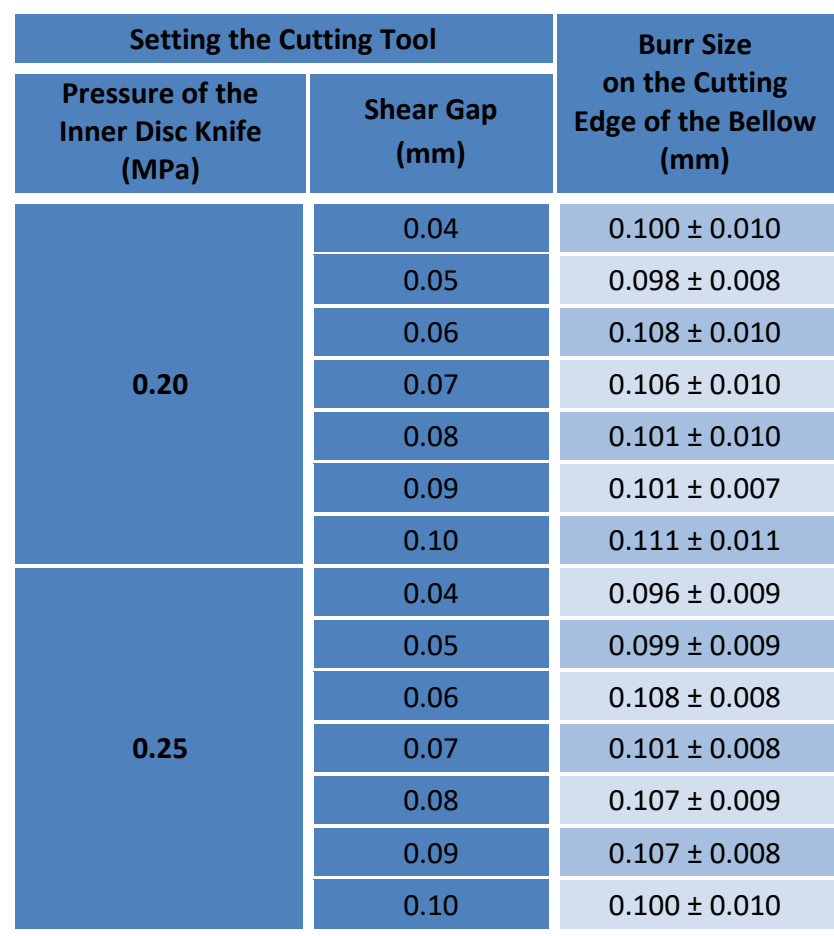

Table 7. Medium-sized burr (with random error) at the cutting edge of a bellow cut by the tool set with wear after 120,000 tool cycles

\begin{tabular}{|c|c|c|c|c|}
\hline \multicolumn{2}{|c|}{ Setting the Cutting Tool } & \multicolumn{3}{|c|}{ Size of the Burr at Individual Points of the Shearing Surface on the Bellows } \\
\hline $\begin{array}{l}\text { Pressure of the Inner } \\
\text { Disc Knife } \\
\text { (MPa) }\end{array}$ & $\begin{array}{l}\text { Shear Gap } \\
\quad(\mathrm{mm})\end{array}$ & $\begin{array}{c}\text { Mean Value } \\
\text { in Places } \alpha^{\prime} \text { and } \alpha^{\prime \prime} \\
(\mathrm{mm})\end{array}$ & $\begin{array}{c}\text { Mean Value } \\
\text { in Places } \beta^{\prime} \text { and } \beta^{\prime \prime} \\
(\mathrm{mm})\end{array}$ & $\begin{array}{c}\text { Mean Value } \\
\text { in Places } \alpha^{\prime}, \alpha^{\prime \prime}, \beta^{\prime} \text { and } \beta^{\prime \prime} \\
(\mathrm{mm})\end{array}$ \\
\hline \multirow{7}{*}{0.20} & 0.04 & $0.024 \pm 0.004$ & $0.141 \pm 0.014$ & $0.082 \pm 0.007$ \\
\hline & 0.05 & $0.025 \pm 0.007$ & $0.136 \pm 0.014$ & $0.080 \pm 0.007$ \\
\hline & 0.06 & $0.027 \pm 0.007$ & $0.141 \pm 0.011$ & $0.084 \pm 0.005$ \\
\hline & 0.07 & $0.034 \pm 0.010$ & $0.146 \pm 0.016$ & $0.090 \pm 0.010$ \\
\hline & 0.08 & $0.038 \pm 0.011$ & $0.140 \pm 0.006$ & $0.089 \pm 0.006$ \\
\hline & 0.09 & $0.032 \pm 0.007$ & $0.135 \pm 0.014$ & $0.084 \pm 0.009$ \\
\hline & 0.10 & $0.044 \pm 0.013$ & $0.126 \pm 0.012$ & $0.085 \pm 0.009$ \\
\hline \multirow{7}{*}{0.25} & 0.04 & $0.026 \pm 0.004$ & $0.139 \pm 0.016$ & $0.082 \pm 0.008$ \\
\hline & 0.05 & $0.025 \pm 0.004$ & $0.149 \pm 0.017$ & $0.087 \pm 0.007$ \\
\hline & 0.06 & $0.034 \pm 0.007$ & $0.146 \pm 0.016$ & $0.090 \pm 0.009$ \\
\hline & 0.07 & $0.032 \pm 0.008$ & $0.132 \pm 0.010$ & $0.090 \pm 0.007$ \\
\hline & 0.08 & $0.040 \pm 0.016$ & $0.134 \pm 0.012$ & $0.087 \pm 0.011$ \\
\hline & 0.09 & $0.040 \pm 0.010$ & $0.141 \pm 0.012$ & $0.090 \pm 0.005$ \\
\hline & 0.10 & $0.040 \pm 0.016$ & $0.129 \pm 0.009$ & $0.087 \pm 0.010$ \\
\hline
\end{tabular}

Table 8. Mean burr sizes (with random error) at separate locations at the cutting surface of a bellow cut by the tool set with wear after 20,000 working cycles

\section{DISCUSSION}

The experimentally determined values of the burr at the cutting edge of the bellows as a function of the shear gap size for internal blade pressures of $0.20 \mathrm{MPa}$ and $0.25 \mathrm{MPa}$ using a wear-resistant tool set after 120,000 working cycles are shown in Fig. 5. From Fig. 5, it can be seen that the optimal setting of the shear gap size is $0.04-0.05 \mathrm{~mm}$ to achieve the lowest burr sizes. The difference between the highest and lowest burr sizes is small $(0.08 \mathrm{~mm})$.

The experimentally determined burr magnitudes at the cutting edge of the bellows as a function of the shear gap size for inner blade pressures of $0.20 \mathrm{MPa}$ and $0.25 \mathrm{MPa}$ using the tool set with wear after 20,000 cycles of operation, measured at the locations of the vertical axis of the upper and lower parts of the outer blade (locations $\alpha^{\prime}$ and $\alpha^{\prime \prime}$ in Fig. 4) are shown in Fig. 6 . Here again, the most suitable setting is a shear gap in the range of $0.04-0.05 \mathrm{~mm}$ at the inner blade pressure of $0.20 \mathrm{MPa}$ and $0.25 \mathrm{MPa}$. The size of the burr is very similar on the perimeter of the shear surface (except for the $\beta^{\prime}$ and $\beta^{\prime \prime}$ locations).

The burr magnitudes experimentally determined at the cutting edge of the bellows as a function of the size of the shear gap for internal blade pressures of $0.20 \mathrm{MPa}$ and $0.25 \mathrm{MPa}$ using 
the tool set with wear after 20,000 cycles, measured at the points formed by the edges of the upper and lower parts

of the outer blade (locations $\beta^{\prime}$ and $\beta^{\prime \prime}$ in Fig. 4) are shown in Fig. 7.

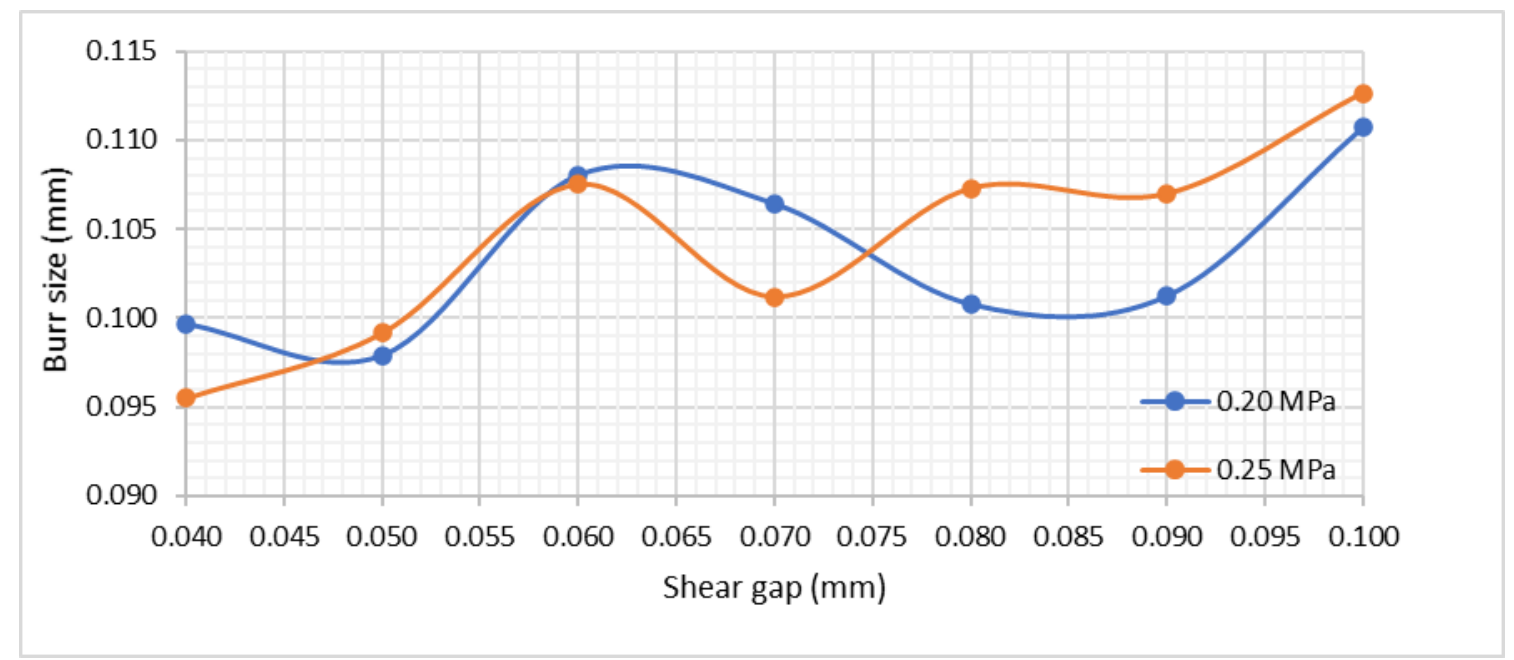

Figure 5. Experimentally determined burr sizes at the cutting edge of the bellows as a function of the shear gap size for internal blade pressures of $0.20 \mathrm{MPa}$ and $0.25 \mathrm{MPa}$ using a tool set with wear after 120,000 cycles

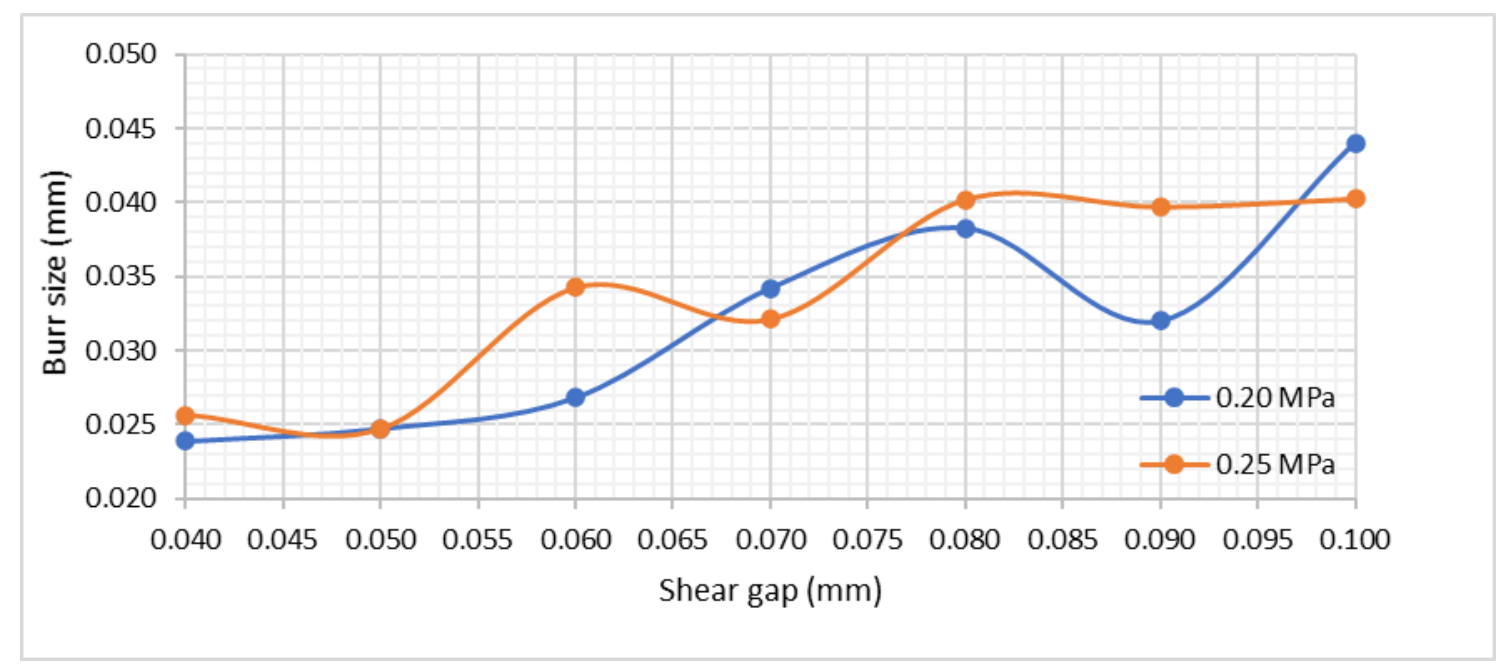

Figure 6. Experimentally determined burr magnitudes at the cutting edge of the bellows as a function of the shear gap size for internal blade pressures of $0.20 \mathrm{MPa}$ and $0.25 \mathrm{MPa}$ using a tool set with wear after 20,000 cycles, measured at the locations of the vertical axis of the top and bottom of the outer blade (locations $\alpha^{\prime}$ and $\alpha^{\prime \prime}$ in Fig. 4)

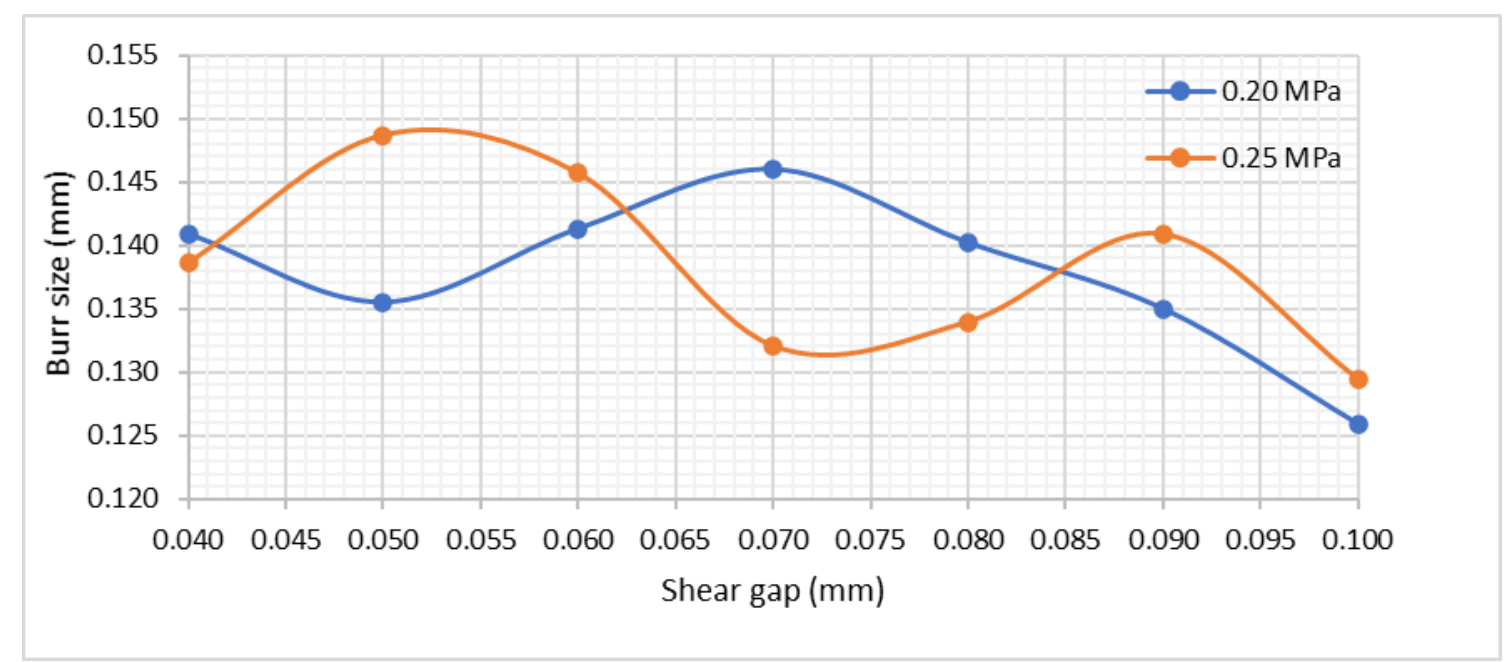

Figure 7. Experimentally determined burr magnitudes at the cutting edge of the bellows as a function of the shear gap size for internal disc knife pressures of $0.20 \mathrm{MPa}$ and $0.25 \mathrm{MPa}$ using a tool set with wear after 20,000 working cycles, measured at the points formed by the edges of the upper and lower parts of the external knife (points $\beta^{\prime}$ and $\beta^{\prime \prime}$ in Fig. 4) 
In Fig. 7, the most suitable settings for achieving a minimum burr are a shear gap of $0.1 \mathrm{~mm}$ and an inner blade pressure of $0.20 \mathrm{MPa}$. The maximum burr size within the optimum shear gap mentioned above of 0.04 to $0.05 \mathrm{~mm}$ is $(0.149 \pm 0.017) \mathrm{mm}$. Therefore, the specified value of $0.17 \mathrm{~mm}$, determined by the manufacturer as the limiting value for subsequent deburring of the bellows by plastering technology, is not exceeded.
Experimentally determined burr sizes at the cutting edge of the bellows as a function of the shear gap size for internal blade pressures of $0.20 \mathrm{MPa}$ and $0.25 \mathrm{MPa}$ using a set of tools with wear after 20,000 cycles - the mean values from four measured points on the perimeter of the cutting surface (points $\alpha^{\prime}, \alpha^{\prime \prime}, \beta^{\prime}$ and $\beta^{\prime \prime}$ in Fig. 4) are shown in Fig. 8 . Fig. 8 shows the suitability of setting the shear gap size to $0.05 \mathrm{~mm}$ and the pressure of the inner blade to 0.20 MPa.

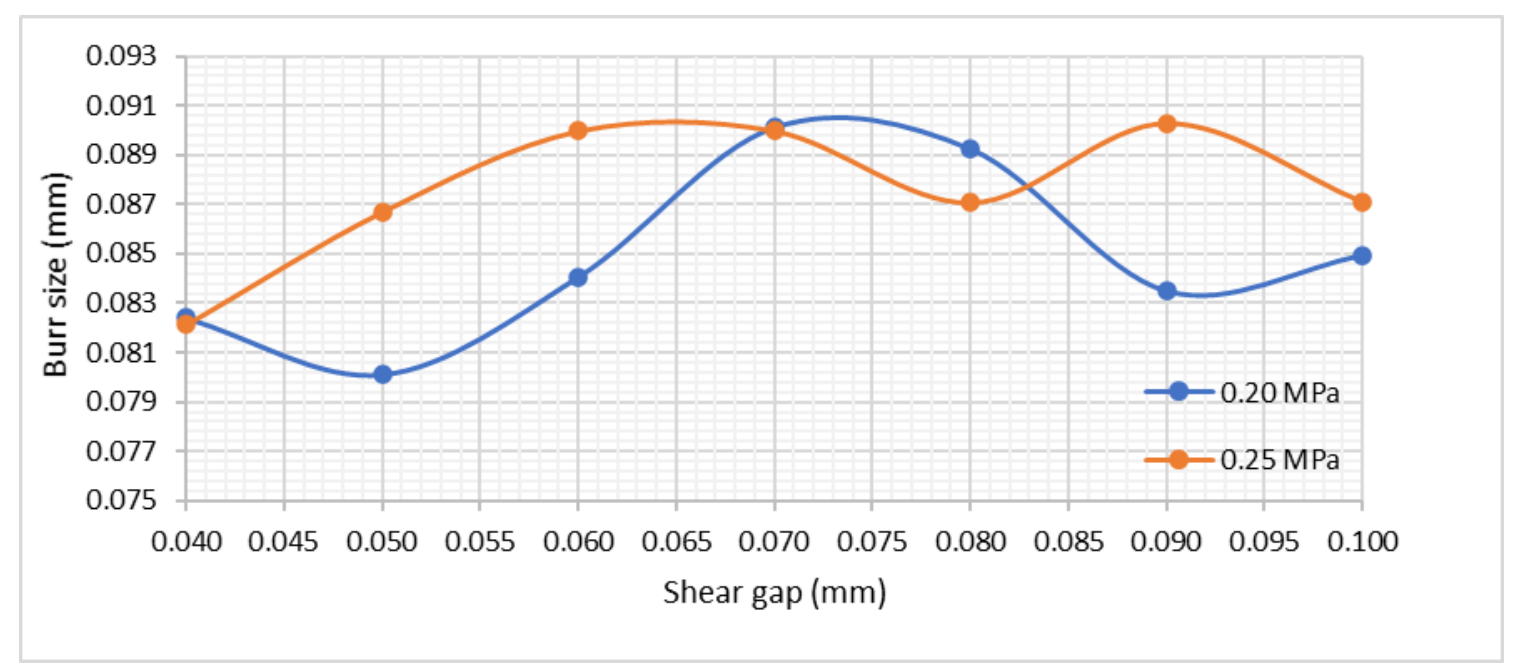

Figure 8. Experimentally determined burr magnitudes at the cutting edge of the bellows as a function of the shear gap size for internal blade pressures of $0.20 \mathrm{MPa}$ and $0.25 \mathrm{MPa}$ using a tool set with wear after 20,000 working cycles - mean values from 4 measured locations on the shear perimeter (locations $\alpha^{\prime}, \alpha^{\prime \prime}, \beta^{\prime}$ and $\beta^{\prime \prime}$ in Fig. 4)

\section{CONCLUSIONS}

This paper focused on optimizing the size of the shear gap as well as the pressure of the inner disc knife to minimize the size of the burr after cutting the bellows. For experimental evaluation, a bellow with an outer diameter of $15 \mathrm{~mm}$, with a wall thickness of $0.4 \mathrm{~mm}$, made of 1.4541 was used.

Using a tool set with wear after 20,000 cycles, an optimum shear gap size of 0.04 to $0.05 \mathrm{~mm}$ was found at locations $\alpha^{\prime}$ and $\alpha^{\prime \prime}$ (see Fig. 4) at both applied internal blade pressures, i.e. $0.20 \mathrm{MPa}$ and 0.25 MPa (see Tab. 4 and Fig. 6).

From the measurement results using a tool set with wear after 120,000 cycles, it is clear that the optimum setting of the shear gap size is also 0.04 to $0.05 \mathrm{~mm}$ to achieve the lowest burr sizes (see Tab. 3 and Fig. 5).

The detected values of the shearing gap size will allow optimal adapting of the shearing tool to achieve the minimum size of the burr on the edge of the bellows shearing surface, which will allow reducing the time of the subsequent operation of removing burrs by plastering or brushing and thus cheapen the production of bellows. The values found will also allow for optimisation of the shearing tool setting for bellows and tubes made of the same material or a material with very similar mechanical properties.

In the experimental analysis, it was found that the maximum burr sizes occur at the cutting edge of the bellows at locations corresponding to the edges of the upper and lower parts of the outer blade (locations $\beta^{\prime}$ and $\beta^{\prime \prime}$ in Fig. 4). At these locations, the maximum burr size was found to be $(0.149 \pm 0.017) \mathrm{mm}$ for an internal blade pressure of $0.25 \mathrm{MPa}$ and a shear gap size of $0.05 \mathrm{~mm}$ using a tool set with wear after 20,000 cycles (see Tab. 8 and Fig. 7). The maximum burr size observed is less than $0.17 \mathrm{~mm}$, which was established by the bellows and tube manufacturer as the limiting value due to the subsequent deburring operation.

Using a tool set with a higher wear rate (with wear after 120,000 cycles) during the experimental analysis, the mean value of the burr size was determined at different shear gap sizes and internal blade pressures (see Tab. 3 and Fig. 5). These values can be used to assess the magnitude of the burr as a function of the wear of the inner disc knives and the outer two-piece knives.

The mentioned procedure can be applied to analogous cases of division.

\section{ACKNOWLEDGMENTS}

This work was supported by the SP2021/104 specific research project at the Faculty of Mechanical Engineering of VSB Technical University of Ostrava.

\section{REFERENCES}

[Cada 1997] CADA, R. Formability of Deep-Drawing Steel Sheets. In: Materials, Functionality \& Design, Proceedings of the 5th European Conference on Advanced Materials and Processes and Applications EUROMAT 97. Maastricht, The Netherlands, 1997, pp. 463-466, ISBN 90-803513-4-2.

[Cada 2003] CADA, R. Testing of Strain in Stampings by Embossed Grids. Technical Gazette, 2003, Vol. 10, No. 3-4, pp. 9-13. ISSN 1330-3651.

[Cada 2003] CADA, R. Evaluation of Strain and Material Flow in Sheet-Metal Forming. Journal of Materials Processing Technology, 2003, Vol.138, No.1-3, pp. 170-175. ISSN 09240136. 
[Evin 2011] EVIN, E. and KOLLAROVA, M. The Tribology Properties of Zinc Coated Steel Sheets for Auto Body. Chemical Journal, 2011, Vol. 105, No. SI, pp. S465-S467, ISSN 0009-2770.

[Evin 2012] EVIN, E., TOMAS, M. and VYBOCH, J. Prediction of Local Limit Deformations of Steel Sheets Depending on Deformation Scheme. Chemical Journal, 2012, Vol. 106, No. S3, pp. 401-404, ISSN 0009-2770.

[Evin 2016] EVIN, E., TOMAS, M. and VYROSTEK, M. Laser-Beam Welding Impact on the Deformation Properties of Stainless Steels when Used for Automotive Applications. Acta Mechanica Automatica, 2016, Vol. 10, No. 3, pp. 189-194. ISSN 1898-4088.

[Hilser 2020] HILSER, O., RUSZ, S., PASTRNAK, M. and ZABYSTRZAN, R. Tensile Properties and Microhardness Evolution in Medium Carbon Sheets Subjected to Continuous SPD Process. In: $29^{\text {th }}$ International Conference on Metallurgy and Materials (Metal 2020). Ostrava, Czech Republic: TANGER, 2020, pp. 339-343. ISBN 978-80-87294-97-0. ISSN 2694-9296.

[Losak 2021] LOSAK, P. Analysis of Deburring Technologies after Cutting the Material: Bachelor Thesis. Ostrava: VSB - Technical University of Ostrava, 2021, 53 p. (in Czech)

[Necas 2019] NECAS, L. Training and Practice to Ensure Implementation of the TPM System. Modern Machinery (MM) Science Journal, Vol. 12, No. 2 (June), 2019, pp. 4124-4127. ISSN 1803-1269 (Print), ISSN 1805-0476 (Online).

[Novak 2019] NOVAK, V., VALES, M., TATICEK, F., SANOVEC, J. and CHRASTANSKY, L. The Effect of Strain Rate on Position of Forming Limit Curve. In: $28^{\text {th }}$ International Conference on Metallurgy and Materials (Metal 2019). Ostrava, Czech Republic: TANGER, 2019, pp. 450-454. ISBN 978-80-87294-92-5. ISSN 2694-9296.

[Petrkovska 2012] PETRKOVSKA, L. and CEPOVA, L. Metrology and Quality Management: textbook [online]. Ostrava: VSB Technical University of Ostrava, 2012. [cit. 2021-09-19]. $142 \mathrm{~s}$. Available from: $<$ http://projekty.fs.vsb.cz/459/ucebniopory/Metrologie a rize ni kvality.pdf>. ISBN 978-80-248-2771-1. (in Czech)

[Pyszko 2018] PYSZKO, R., FRANEK, Z., PRIHODA, M., VELICKA, M. and SIKORA, K. Monitoring and Simulation of the Unsteady States in Continuous Casting. Materiali in Tehnologije, Vol. 52, No. 2, 2018, pp. 111-117. ISSN 15802949 (Print), ISSN 1580-3414 (Online).
[Rihacek 2019] RIHACEK, J., PODANY, K. and PETERKOVA, E. Liquid as Forming Medium [online]. Praha: MM Prumyslove spektrum, 2019. [cit. 2021-09-24] Available from: <https://www.mmspektrum.com/clanek/kapalina-jako-tvarecimedium.html>. ISSN 1212-2571 (in Czech)

[Rusz 2019] RUSZ, S., HILSER, O., OCHODEK, V., CADA, R., SVEC, J. and SZKANDERA, P. Influence of SPD Process on LowCarbon Steel Mechanical Properties. Modern Machinery (MM) Science Journal, Vol. 12, No. 2 (June), 2019, pp. 2910-2914. ISSN 1803-1269 (Print), ISSN 1805-0476 (Online).

[Rusz 2020] RUSZ, S., HILSER, O., OCHODEK, V., CIZEK, L., KRAUS, M., MARES, V., GRAJCAR, A. and SVEC, J. Effect of Severe Plastic Deformation on Mechanical and Fatigue Behavior of Medium-C Sheet Steel. Journal of Mining and Metallurgy: Section B-Metallurgy, Vol. 56, No. 2, 2020, pp. 161170. ISSN 1450-5339 (Print), ISSN 2217-7175 (Online).

[Sajdlerova 2015] SAJDLEROVA, I., GREGUSOVA, M. and SCHINDLEROVA, V. Potential of Value Stream Mapping Utilization in the Seamless Steel Tubes Manufacturing Process. In: $24^{\text {th }}$ International Conference on Metallurgy and Materials (Metal 2015). Ostrava, Czech Republic: TANGER, 2015, pp. 2056-2064. ISBN 978-80-8729462-8.

[Sternadelova 2019] STERNADELOVA, K., MOHYLA, P., TROMBIK, M. and KRUPOVA, H. Properties and Microstructure of Modeled Heat-Affected Zone of P92 Steel. In: $28^{\text {th }}$ International Conference on Metallurgy and Materials (Metal 2019). Ostrava, Czech Republic: TANGER, 2019, pp. 832-836. ISBN 978-80-87294-92-5. ISSN 2694-9296.

[Velicka 2013] VELICKA, M., DITTEL, D., PYSZKO, R., PRIHODA, M., VACULIK, M., FOJTIK, P. and BURDA, J. Research of Thermal Processes for the Continuous Casting of Steel. Materiali in Tehnologije, 2013, Vol. 47, No.6, pp.815-818. ISSN 1580-2949.

[Vontorova 2018] VONTOROVA, J. and MOHYLA, P. Use of GDOES Method for Evaluation of the Quality and Thickness of Hot Dip Galvanised Coating. Transactions of the Institute of Metal Finishing, 2018, vol. 96, No. 6, pp. 313-318. ISSN 00202967 (Print), ISSN 1745-9192 (Online).

\section{CONTACT:}

prof. Ing. Radek Cada, CSc.

VSB - Technical University of Ostrava, Faculty of Mechanical Engineering, Department of Mechanical Technology

17. Listopadu 2172/15, 70800 Ostrava-Poruba, Czech Republic

tel.: +420597323289, e-mail: radek.cada@vsb.cz

www.fs.vsb.cz 